\title{
Relationship between Patient Cooperation and Treatment Result among Orthodontic Patients in Biratnagar, Nepal
}

\author{
Dr Anand Acharya,' Dr Bhushan Bhattarai, ${ }^{2}$ Dr Dhirendra Giri, ${ }^{3}$ Dr Tarakant Bhagat4 \\ 1.2Lecturer, Dept of Orthodontics, ${ }^{3}$ Asst Prof, Dept of Periodontics, Nobel Medical College, Biratnagar, \\ ${ }^{4}$ Assoc Prof, Dept of Public Health Dentistry, BP Koirala Institute of Health Sciences, Dharan, Nepal
}

Correspondence: Dr Anand Acharya; Email: dranandacharya@gmail.com

\section{ABSTRACT}

Introduction: Orthodontic treatment is a highly technique sensitive process; which takes long duration and its success depend on many factors. Patient cooperation is one of the important determinants of orthodontic treatment.

Objective: To investigate the relationship between patients' cooperation and orthodontic treatment result as rated by the orthodontist.

Materials \& Method: Orthodontic Patient Cooperation Scale (OPCS) was used to evaluate 57 orthodontic patients' cooperation who had undergone active orthodontic treatment in Nobel Medical College Hospital, Biratnagar from 2014 January to 2017 June and were under retention phase. Orthodontic treatment results of these patients were graded as good, acceptable and poor by the orthodontist. Independent t-test was applied to test the mean of OPCS score, the treatment result and gender.

Result: Mean OPCS score was higher in good treatment result category; as the OPCS score increased treatment result improved, which was statistically significant $(p<0.01)$.

Conclusion: Orthodontic patients' cooperation is a strong determining factor for positive treatment outcome.

Keywords: Orthodontic Patient Cooperation Scale, orthodontic treatment

\section{INTRODUCTION}

Successful outcome of orthodontic treatment does not only depend on the competency on part of the treating orthodontist but also on patients' obedience towards orthodontist's instructions. The extent to which a patient benefits from orthodontic treatment depends upon patient cooperation in the treatment.' Many researchers have developed the scale to predict patient cooperation. ${ }^{1-5}$

Slakter et al introduced Orthodontic Patient Cooperation Scale (OPCS) on the basis of ten patient behaviors.' This scale has adequate internal consistency to be used as a means to measure the patient cooperation. There are different factors influencing orthodontic treatment. This was given by a fish bone diagram. ${ }^{6}$ Out of the multitude of factors our study used 'patient cooperation during orthodontic treatment' as the factor influencing orthodontic treatment result categorized as good, acceptable and poor. Nepalese studies concerning patient cooperation and orthodontic treatment result are rare. Hence, the objective of our study was to rate orthodontic patients' cooperation in Biratnagar according to OPCS and to compare their cooperation with the treatment results rated by the orthodontist.

\section{MATERIALS AND METHOD}

Orthodontic Patient Cooperation Scale (OPCS) was used to rate 57 orthodontic patients (40 female and 17 male) who had undergone active orthodontic treatment in Nobel Medical College Teaching Hospital, Biratnagar from 2014 January to 2017 June. Ethical clearance was obtained from the Institutional Review Committee and written informed consent was obtained from parent/ guardian and assent from the patient.

Inclusion criteria were: orthodontic patients aged 12-19 years accompanied by guardians during diagnosis and treatment plan appointments, patients under retention phase after completing active fixed orthodontic therapy; presence of case history, pre- and post-treatment records; no history of trauma.

Revised questionnaire with 5-point Likert scale was used to assess patient's cooperation (Table 1).' The assessment 
Table 1: Questionnaire used to assess patient cooperation

\section{This patient keeps appointments and is prompt.}

() Always () Frequently () Sometimes () Rarely () Never

2. This patient has distorted wires and/or loose bands.

() Always () Frequently () Sometimes () Rarely () Never

3. The parent(s) of this patient is (are) observed to be interested and involved in treatment.

() Always () Frequently () Sometimes () Rarely () Never

4. This patient speaks of family problems or a poor relationship with parent(s) or demonstrates such problems in interactions with parent(s) which I have observed.

() Always () Frequently () Sometimes () Rarely () Never

5. This patient acts enthusiastic and interested in treatment.

() Always () Frequently () Sometimes () Rarely () Never

6. This patient's behavior is sullen, hostile, belligerent, or rude.

() Always () Frequently () Sometimes () Rarely () Never

7. This patient cooperates in the use of headgear and/or elastics.

() Always () Frequently () Sometimes () Rarely () Never

8. This patient complains about treatment procedures.

() Always () Frequently () Sometimes () Rarely () Never

9. This patient demonstrates excellent oral hygiene

() Always () Frequently () Sometimes () Rarely () Never

10. This patient complains about having to wear braces.

() Always () Frequently () Sometimes () Rarely () Never

Table 2: Scoring criteria used to assess treatment result

\begin{tabular}{l|l|}
$\begin{array}{l}\text { Score 1 } \\
\text { Poor }\end{array}$ & $\begin{array}{l}\text { Treatment result does not coincide with the treatment goal. } \\
\text { Malocclusion persists and only minor changes have occurred. }\end{array}$ \\
\hline $\begin{array}{l}\text { Score 2 } \\
\text { Acceptable }\end{array}$ & $\begin{array}{l}\text { Result coincides in part with the treatment goal. } \\
\text { Signs of severity of malocclusion have been reduced; }\end{array}$ \\
\hline $\begin{array}{l}\text { Score 3 } \\
\text { Good }\end{array}$ & $\begin{array}{l}\text { Treatment normal relations (< half a cusp-width) } \\
\text { Minor rotations or slight irregularities of single teeth may, however be allowed. }\end{array}$ \\
\hline
\end{tabular}

was done by trained and calibrated Orthodontists on patients meeting inclusion criteria. Treatment result of each patient was evaluated with the help of pre- and posttreatment records by Orthodontists as good, acceptable and poor (Table 2).5 Each patient was rated according to the scale by a different Orthodontist to avoid observer bias. Independent t-test was used to test the mean of OPCS scores, treatment results and gender. SPSS version 11.5 was used to analyze the data, level of significance was set at $p<0.05$.

\section{RESULT}

Out of 57 patients, 40 (70.2\%) were female and $17(29.8 \%)$ were male, mean age of the patients was
15.29 years (SD 1.92). Good treatment result was seen in 34 subjects and acceptable treatment result was seen in 23 subjects. There was no poor treatment result. The mean score for good treatment result was 47.46 (SD 0.900) and that for acceptable treatment result was 43.95 (SD 3.818).

Independent t-test was applied to test the mean OPCS score, treatment result and gender. Mean OPCS score was higher in good treatment result category and as the OPCS score increased, the treatment result improved which was statistically significant $(p<0.01)$. It was also observed that the mean OPCS score was higher in females compared to males but was not statistically 
Table 3: Comparison between mean OPCS score, Orthodontic treatment result and gender

\begin{tabular}{|c|c|c|c|c|}
\hline \multicolumn{3}{|c|}{ Orthodontic Patient Cooperation Scale } & $t$-Value & $p$-Value \\
\hline \multirow{2}{*}{ Mean score } & Good & Acceptable & \multirow{2}{*}{-4.050} & \multirow{2}{*}{$0.001^{*}$} \\
\hline & $47.46 \pm 0.900$ & $43.95 \pm 3.818$ & & \\
\hline \multirow{2}{*}{ Gender } & Female & Male & \multirow{2}{*}{1.560} & \multirow{2}{*}{0.136} \\
\hline & $46.75 \pm 1.645$ & $45.00 \pm 4.500$ & & \\
\hline \multirow{2}{*}{\multicolumn{3}{|c|}{ Orthodontic Treatment Result }} & $\chi^{2}$ value & \multirow{2}{*}{0.217} \\
\hline & & & 1.524 & \\
\hline
\end{tabular}

*Statistically significant at $p<0.05$

significant $(p=0.136)$. Chi square test was applied to find the difference in the treatment outcome among gender. The difference in orthodontic outcome among gender was not statistically significant $\left(\chi^{2}=1.524, p=\right.$ 0.217 ) (Table 3).

\section{DISCUSSION}

The high mean OPCS score in patients under good treatment result category shows that good patients cooperation is needed for better treatment results which is consistent with the previous research. ${ }^{7}$ Higher mean cooperation score in females, though not statistically significant; is in accordance with the previous research. ${ }^{8}$

The difference in orthodontic treatment result among gender groups was not statistically significant which shows orthodontic treatment result does not depend on the gender but is determined by the degree of cooperation in following orthodontist's instructions. Factors that might significantly predict patient's cooperation with orthodontic treatment include patient's attitude toward the treatment immediately before and during the treatment and the ability to cope with any discomfort during the treatment. ${ }^{9}$

It has been established that orthodontist's behavior influence patient satisfaction, the orthodontist-patient relationship and patient cooperation. ${ }^{10}$ Positive reinforcement by praising the patients verbally when they show good cooperation is generally used in routine clinical practice."

\section{CONCLUSION}

Every effort should be undertaken to render the patient as cooperative as possible so as to carry out the orthodontic treatment smoothly and finally obtain the best treatment result. Further research is necessary to include other factors that can affect the orthodontic outcome such as severity of malocclusion, choice of the appliance and competency of the orthodontist.

\section{REFERENCES}

1. Slakter MJ, Albino JE, Fox RN, Lewis EA. Reliability and stability of the orthodontic patient cooperation scale. Am J Orthod. 1980;78:559-632.

2. Mehra T, Nanda RS, Sinha PK. Orthodontists' assessment and management of patient compliance. Angle Orthod. 1998;68:115-22.

3. Sergl HG, Klages U, Zentner A. Pain and discomfort during orthodontic treatment: causative factors and effects on compliance. Am J Orthod Dentofac Orthop. 1998;114: 684-91.

4. Sergl HG, Klages U, Pempera J. On the prediction of dentist-evaluated patient compliance in orthodontics. Eur J Orthod. 1992;14:463-8.

5. Bergström K, Halling A, Huggare J, Johansson L. Treatment difficulty and treatment outcome in orthodontic care. Eur J Orthod. 1998;20:145-157.

6. Ishikawa, K. What is total quality control? The Japanese way. Englewood Cliffs, Prentice-Hall, New York 1985.

7. Adam S. Daniels, Jason D. Seacatand Marita Rohr Inglehart. Orthodontic treatment motivation and cooperation; a cross-sectional analysis of child and adolescent patients and parents responses. Am J Orthod Dentofac Ortho. 2009;136:780-7.

8. Edward J Clemmer, Eugene W. Hayes. Patient cooperation in wearing orthodontic headgear. Am J Orthod Dentofac Ortho. 1979;75:5:517-24.

9. Brattstrom V, Ingelsson M, Aberg E. Treatment co-operation in orthodontic patients. Br J Orthod. 1991;18:37-42.

10. Cohen L. Social psychological factors associated with malocclusion. Int Dent J. 1970;20:643-53.

11. Contemporary Orthodontics, 4th Ed., William R Proffit, Mosby 2007;6:167-233. 